\title{
ANALISIS PENINGKATAN KUALITAS PEMOTONGAN AYAM DENGAN MENGGUNAKAN METODE SIX SIGMA DI PT.GEMILANG INTI SUKSES
}

\author{
Ahmad Sukron \\ Teknik Industri, Fakultas Teknik, Universitas Hasyim Asy’ari, Email : ac.syuk212@gmail.com
}

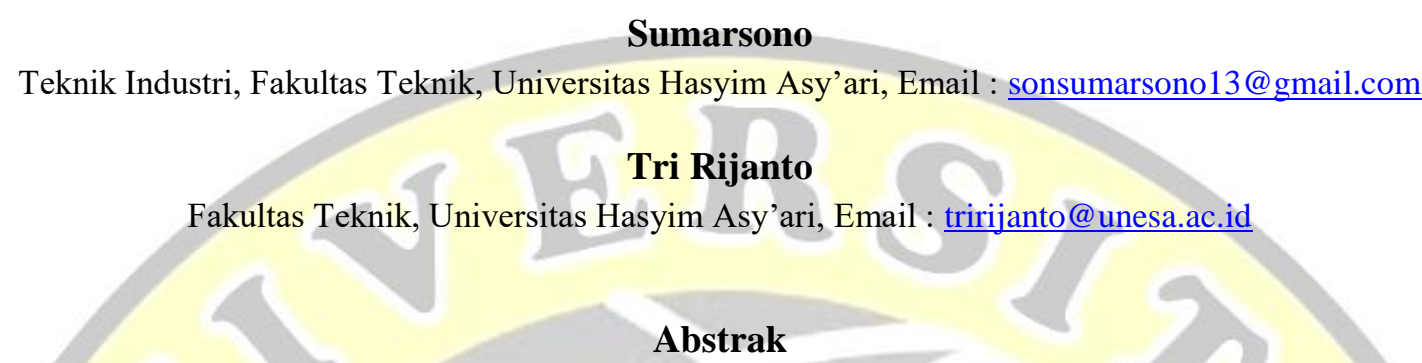

Kegiatan peningkatan kualitas dapat membantu perusahaan dalam mempertahankan dan meningkatkan kualitas produknya dengan melakukan perbaikan terhadap tingkat kerusakan produk sampai pada tingkat kerusakan nol. PT. Gemilang Inti Sukses merupakan sebuah Industri Rumah Porong Ayam berorientasi Profit yang bergerak di sektor agribisnis, dalam proses pemotongan ayam terdapat beberapa kendala yang dapat mempengaruhi tingkat kualitas produk hasil potong ayam, Oleh sebab itu penelitian ini bertujuan untuk mengetahui permasalahan kualitas pemotongan ayam dan mendapatkn hasil peningkatan kualitas produk di PT. Gemilang Inti Sukses. Metode yang akan digunakan dalam penelitian ini adalah metode Six Sigma pada konsep DMAIC (Define, Measure, Analyze, Improve, Control). Hasil penelitian menunjukkan bahwa dari jumlah sampel selama 20 hari yakni 6.540 ekor diketahui jumlah hasil pemotongan ayam yang cacat sebanyak 2.230 ekor ayam dengan rincian bagian kepala ayam memar, bagian sayap ayam patah, bagian tubuh ayam memar, pencabutan bulu kurang bersih, dan pengambilan bagian dalam kurang bersih. Sedangkan pengukuran kinerja perusahaan berada pada level Sigma 3,85 dengan nilai DMPO 9.292 yang artinya dalam 1 juta potong ayam terdapat 9.292 ekor ayam yang cacat. Dari diagram diagram pareto diketahui $80 \%$ penyebab cacat adalah bagian sayap ayam patah dan bagian tubuh ayam memar. Kemudian dari diagram sebab akibat diketahui bahwa faktor sumber daya manusia menjadi penyebab utama dari cacat sayap ayam patah dan bagian tubuh ayam memar, oleh sebab itu dari hasil penelitian ini maka perusahaan perlu melakukan peningkatan kualitas dengan kedisiplinan yang lebih terhadap stardar operasional sumber daya manusia dan melakukan pengawasan serta evaluasi kinerja karyawan.

Kata Kunci: Pareto, Peningkatan Kualitas,Sebab Akibat, Six Sigma-DMAIC.

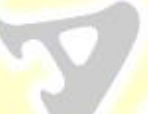

\section{Abstract}

Quality improvement activities can help companies maintain and improve the quality of their products by making improvements to the level of being broken product to zero damage. PT. Gemilang Inti Sukses is a Profit-oriented Chicken Porong Home Industry engaged in the agribusiness sector, in the process of cutting chickens there are several obstacles that can affect the level of quality of chicken slaughtered products, Therefore this study aims to determine the quality problems of chicken slaughter and increase the results product quality at PT. Gemilang Inti Sukses. The method that will be used in this research is the Six Sigma method on the DMAIC (Define, Measure, Analyze, Improve, Control) concept. The results showed that of the 20 days sample that was 6,540 tails, it was found that the number of slaughtered chickens was 2,230 chickens with the details of bruised chicken heads, broken chicken wings, bruised chicken body parts, less clean feather extraction, and internal taking. not clean enough. While the company's performance measurement is at Sigma 3.85 level with a 9.292 DMPO value, which means that in 1 million pieces of chicken there are 9,292 chickens that are deformed. From the Pareto diagram, it is known that $80 \%$ of the defects are broken chicken wings and bruised chicken parts. Then from the cause and effect diagram it is known that human resource factors are the main cause of broken chicken wing flaws and bruised chicken body parts, therefore from the results of this study the company needs to improve quality with more discipline towards human resource operational standards and conduct supervision and evaluation of employee performance.

Keywords: Pareto, Quality Improvement, Cause and Effect, Six Sigma-DMAIC. 


\section{PENDAHULUAN}

Kemajuan dan perkembangan zaman membuat beruah cara pandang konsumen dalam memilih sebuah produk yang diinginka. Kualitas menjadi sangant penting dalam memilih sebuah produk di samping faktor harga yang bersaing. Kegiatan peningkatan kualitas dapat membantu perusahaan dalam mempertahankan dan meningkatkan kualitas produknya dengan melakukan perbaikan terhadap tingkat cacat produk sampai pada tingkat kerusakan nol. Meskipun proses produksi sudah dilaksanakan dengan baik, pada kenyataannya masih sering ditemukan ketidaksesuaian antara produk yang dihasilkan dengan yang diharapkan, dimana kualitas produk yang dihasilkan tidak sesuai dengan standar atau masih ada kecacatan produk (Prawira, 2014:1).

PT. Gemilang Inti Sukses adalah sebuah industri Rumah Potong Ayam (RPA) berorientasi Profit yang bergerak disektor agribisnis. Sebagai badan usaha baru banyak hal yang harus disiapkan dan ditingkatkan untuk dapat mencapai misi bisnis perusahaan. Misi tersebut adalah mengejar pertumbuhan, laba, kemajuan teknologi, dan organisasi, yang semua itu orientasi akhirnya adalah peningkatan pendapatan dan kesejahteraan. Dari hasil wawancara yang dilakukan oleh peneliti kepada pihak kepala produksi, PT. Gemilang Inti Sukses tiap harinya mampu memotong ayam sebanyak 18-19 ton ekor ayam, dan dalam proses pemotongan tersebut hasil yang didapatkan tidak semua bagus. Dimana hasil tersebut masih banyak yang mengalami cacat. PT. Gemilang Inti Sukses sebelumnya tidak pernah memakai metode apapun untuk mengatasi masalah tersebut.

Berdasarkan uraian di atas diketahui adanya masalah dalam kualitas pemotongan ayam di PT. Gemilang Inti Sukses, sehingga penulis berpikiran tentang bagaimana menghilangkan cacat atau meningkatkan kualitas pemotongan ayam tersebut dengan mengunakan metode Six Sigma. Alasan penulis menggunakan metode Six Sigma karena metode Sig Sigma dapat meningkatkan mutu produksi dan penghematan biaya ditengan persaingan bisnia yang mematikan.

Berdasarkan lantar belakang permasalahan diatas yang menjadi rumusan masalah untuk penelitian ini adalah bagaimana mengidentifikasai permasalahan kualitas pemotongan ayam dan hasil peningkatan kualitas pemotongan ayam dengan menggunakan metodeSix Sigma di PT. Gemilang Inti Sukses.

\section{METODE}

Penelitian ini menggunakan metode Six Sigma dengan konsep DMAIC (Define, Measure, Analyze, Improve, Control) dilakukan di PT. Gemilang Inti Sukses yang berada di Desa Gondek, Kecamatan Mojowarno,
Kabupaten Jombang. Objek penelitian ini adalah produk ayam yang mengalami cacat yang tidak memenuhi standar perusahaan sendiri dan swalayan di bagian proses produksi pemotongan ayam PT. Gemilang Inti Sukses. Kemudian langkah penelitian ini adalah sebagai berikut :

\section{Latar Belakang}

PT. Gemilang Inti Sukses tersebut tiap harinya mampu memotong ayam sebanyak 18-19 ton ekor ayam, dan dalam proses pemotongan tersebut hasil yang didapatkan tidak semua bagus, dimana dalam pemotongan tersebut sebagian ada yang mengalami cacat (reject), seperti sayap ayam patah, kaki ayam patah, bagian tubuh ayam ada yang hancur dan lain sebagainya. Hal tersebut disebabkan adanya kesalahan dari berbagai faktor, baik faktor yang berasal dari bahan baku, tenaga kerja maupun dari alat ataupun fasilitas mesin yang digunakan dalam proses produksi.

Rumusan Masalah
$\begin{aligned} & \text { Bagaimana mengidentifikasi masalah kualitas dan hasil } \\ & \text { kualitas pemotongan ayam menggunakan metode Six } \\ & \text { Sigma di PT. Gemilang Inti Sukses? }\end{aligned}$

Tujuan Masalah

Mengidentifikasi masalah kualitas dan mendapatkan hasil kualitas pemotongan ayam menggunakan metode Six Sigma di PT. Gemilang Inti Sukses.

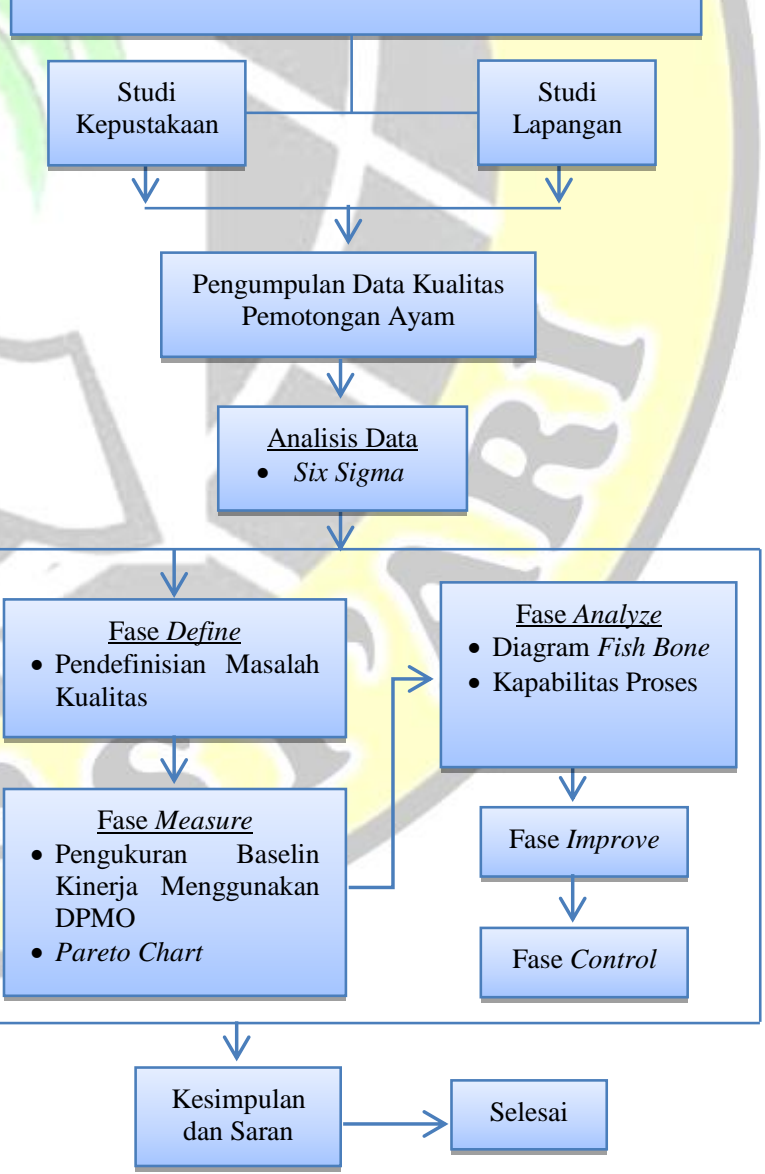

Gambar 1. Langkah-langkah Penelitian 
Pengolahan data yang dilakukan dalam penelitian ini melalui bebrapa fase, yaitu :

1. Fase Define

Pada fase ini dilakukan observasi untuk menemukan beberapa masalah terjadinya cacat produk menurut PT. Gemilang Inti Sukses. Selanjutnya akan dilakukan pendefinisian rencana tindakan yang harus dilakukan berdasarkan hasil observasi.

2. Fase Measure

Fase ini dilakukan pengukuran baseline kinerja dengan menggunakan parameter DPMO kemudian menentukan nilai Sigma dan menggunakan Pareto Chart untuk membuat peringkat pada hal-hal yang harus diperioritaskan.

Rumus DPMO adalah sebagai berikut :

$$
\text { DPMO }=\frac{\text { Jumlah Kerwsakan }}{\text { Jumlah Semua Produk }} \times 1.000 .000
$$

\section{Fase Analyze}

Fase ini akan dilakukan sebuah analisis sebab utama yang menyebabkan masalah atau faktor-faktor terhadap penyebab terjadinya cacat dan pengukuran kapabilitas proses. Dalam hal ini Tools yang digunakan adalah diagram sebab akibat dan peta kontrol $\mathrm{P}$ yang dirumuskan sebagai berikut :

$$
\begin{aligned}
p=\frac{\sum n p}{\sum n} \quad \text { Dimana }: \mathrm{n} & =\text { Jumlah Sampel } \\
\mathrm{np} & =\text { Jumlah Kecacatan } \\
p & =\text { Rata-rata proporsi kecacatan }
\end{aligned}
$$

menentukan nilai UCL (Upper Control Limit / batas atas) dan LCL (Lowe Control Limit / batas bawah).

$$
\begin{aligned}
& U C L=p+3 \sqrt{\frac{p(1-p)}{n}} \\
& L C L=p-3 \sqrt{\frac{p(1-p)}{n}}
\end{aligned}
$$

\section{Fase Improve}

Fase Improve akan dilakukan perbaikan untuk meningkatkan kualitas proses pemotongan ayam dan menghilangkan sebab cacat pada produk pemotongan ayam berdasarkan hasil yang didapat dari diagram sebab akibat

\section{HASIL DAN PEMBAHASAN}

Pada bagian ini akan dilakukan pengolahan data analisis terhadap data yang diperoleh. Berdasarkan hasil data observasi, diketahui bahwa PT. Gemilang Inti Sukses setiap harinya mampu memotongan ayam kurang lebih sebanyak 18 ton daging ayam, dalam jumlah tersebut berat 1 ekor ayam rata-rata 1,5 kg. Jadi jumlah ayam yang dipotong setiap harinya adalah 12.000 ekor ayam.

Jika hasil pemotongan ayam sebanyak 12.000 ekor ayam, maka jumlah sampel didapatkan dari nilai minimal jumlah sampel menurut slovin yang menggunakan batas toleransi kesalahan 5\% adalah sebagai berikut :

$$
\begin{aligned}
n & =\frac{N}{1+\mathrm{Ne}^{2}} \\
& =\frac{12.000}{1+\left(12.000 \times 0,05^{2}\right)} \\
& =327 \text { ekor ayam perhari }
\end{aligned}
$$

\begin{tabular}{|c|c|c|c|c|c|c|c|}
\hline \multirow{2}{*}{$\begin{array}{l}\text { Minggu } \\
\text { Ke }\end{array}$} & \multirow{2}{*}{ Sampel } & \multicolumn{5}{|c|}{ Sampel Hari Ke } & \multirow{2}{*}{ Jumlah } \\
\hline & & 1 & 2 & 3 & 4 & 5 & \\
\hline 1 & Ayam Cacat & 227 & 106 & 0 & 155 & 0 & 488 \\
\hline 2 & Ayam Cacat & 167 & 103 & 164 & 108 & 63 & 605 \\
\hline 3 & Ayam Cacat & 70 & 237 & 67 & 148 & 99 & 621 \\
\hline 4 & Ayam Cacat & 101 & 0 & 231 & 75 & 109 & 516 \\
\hline
\end{tabular}

Adapun data psoses pengambilan sampel dapat dilihat pada Tabel berikut :

Tabel 1. Data Proses Pengambilan Sampel

Sumber : Hasil Survey Data Primer (2018)

Dari Tabel di atas diketahui bahwa data pengambilan sampel selama 20 hari rata-rata tiap harinya terdapat cacat. Pada minggu ke 1 terdapat cacat 488 ekor ayam, minggu ke 2 sebanyak 605 ekor, minggu ke 3 sebanyak 621 ekor, dan minggu ke 4 sebanyak 516 ekor.

Setelah memperoleh data maka selanjutnya akan dilakukan pengolahan dan analisis dengan menggunakan metode six sigma yang terdiri dari 5 fase, yaitu: fase define, measure analyza, improve, dan control. Uraian fase-fase metode Six Sigma selengkapnya adalah sebagai berikut :

\section{Fase Define}

Pada fase Define merupakan langkah awal dalam melakukan analisa six sigma, yaitu mengidentifikasi hal-hal yang dianggap penting dalam proses produksi pemotongan ayam (Critical to Quality atau CTQ). Berdasarkan hasil interview dengan pihak Quality Control, kepala produksi, dan bagian produksi diketahui bahwa CTQ terdiri dari sortir kuaitas pemotongan ayam yang cacat. Adapun ayam yang cacat seperti bagian kepala ayam memar, bagian sayap ayam patah, bagian tubuh ayam memar, pencabutan bulu kurang bersih, dan pengambilan bagian dalam yang kurang bersih. Hasil survey data primer tersebut dapat dilihat pada Tabel 2.

Tabel 2. Hasil Pemotongan Ayam yang Cacat Selama 20

$$
\text { Hari }
$$

\begin{tabular}{cccccccc}
\hline Mingg & $\begin{array}{c}\text { Bagian } \\
\text { kepala } \\
\text { ayam } \\
\text { memar }\end{array}$ & $\begin{array}{c}\text { Bagian } \\
\text { sayap } \\
\text { ayam } \\
\text { patah }\end{array}$ & $\begin{array}{c}\text { Bagian } \\
\text { tubuh } \\
\text { ayam } \\
\text { memar }\end{array}$ & $\begin{array}{c}\text { Pencab } \\
\text { bulan } \\
\text { bang } \\
\text { yurang } \\
\text { bersih }\end{array}$ & $\begin{array}{c}\text { Penga } \\
\text { mbilan } \\
\text { bagian } \\
\text { dalam } \\
\text { kurang } \\
\text { bersih }\end{array}$ & $\begin{array}{c}\text { Total } \\
\text { Cacat }\end{array}$ & $\begin{array}{c}\text { Jumlah } \\
\text { Produksi }\end{array}$ \\
\hline 1 & 5 & 227 & 254 & 2 & 0 & 488 & 60.000 \\
\hline 2 & 4 & 189 & 403 & 7 & 2 & 605 & 60.000 \\
\hline
\end{tabular}




\begin{tabular}{cccccccc}
\hline 3 & 9 & 295 & 315 & 0 & 2 & 621 & 60.00 \\
\hline 4 & 11 & 249 & 253 & 3 & 0 & 516 & 60.00 \\
\hline Jumlah & 29 & 960 & 1.225 & 12 & 4 & 2.230 & 240.00 \\
\hline
\end{tabular}

Dari tabel di atas diketahui rincian hasil potong ayam yang cacat pada setiap minggunya. Jumlah keseluruhan data hasil pemotongan ayam yang cacat selama 4 minggu sebanyak 2.230 ekor ayam yang terdiri dari lima jenis cacat yaitu pada bagian kepala ayam memar sebanyak 29 ekor, bagian sayap ayam patah sebanyak 960, bagian tubuh ayam memar sebanyak 1.225, pencabutan bulu kurang bersih sebanyak 12 ekor, dan pengambilan bagian dalam yang kurang bersih sebanyak 4 ekor.

2. Fase Measure

Setelah dilakukan pendefinisian masalah yang akan dianalisis, kemudian pada fase measure ini akan dilakukan pengukuran baselin kinerja dan menentukan faktor yang dianggap paling dominan agar dilakukannya perbaikan terhadap proses yang ada.

a. Pengukuran Baseline kinerja menggunakan DPMO

Dalam penelitian ini pengukuran baseline kinerja perusahaan dilakukan dengan menggunakan parameter DPMO dan nilai sigma. Berikut perhitungan sigma pada PT. Gemilang Inti Sukses DPMO $=\frac{\text { Jumlah Kerusakan }}{\text { Jumlah Semua Produk }} \times 1.000 .000$

$=\frac{2.230}{240.000} \times 1.000 .000$

$=9.292$

Dari hasil ini menunjukkan bahwa berdasarkan Tabel konversi Six Sigma (Lampira D), kinerja PT. Gemilang Inti Sukses berada pada level sigma 3,85 dengan nilai DPMO 9.292. Hal ini menunjukkan bahwa baseline kinerja perusahaan kurang baik dan perlu dilakukannya perbaikan kinerja.

b. Diagram Pareto

Dari data yang berada pada Tabel 2. kemuadian selanjutnya akan diukur menggunakan diagram pareto untuk mengetahui jenis cacat yang paling dominan. Diagram pareto dapat dilihat pada Gambar 2.

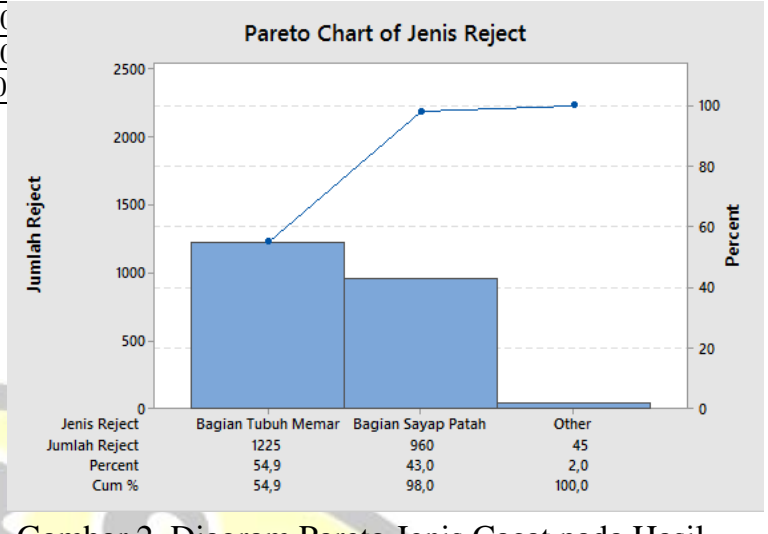

Gambar 2. Diagram Pareto Jenis Cacat pada Hasil Pemotongan Ayam

Dapat dilihat dari Gambar 2. diagram pareto menunjukkan bahwa jenis cacat yang paling doniman terjadi pada bagian tubuh ayam memar sebesar $54,9 \%$ dan bagian sayap ayam patah sebesar $43,0 \%$. Sedangkan jenis cacat yang lainnya hanya 2,0\%, maka jenis cacat tidak akan dimasukkan dalam focus penelitian karena dianggap tidak memberikan pengaruh sebagai penyebab ayam cacat.

3. Fase Analyze

Fase Analyze ini bertujuan untuk menganalisa sebabsebab utama yang menimbulkan masalah pada proses produksi pemotongan ayam. Berdasarkan diagram pareto diketahui bahwa kriteria cacat yang paling dominan adalah bagian tubuh ayam memar dan bagian sayap ayam patah. Untuk mengetahui sebab-sebab utama permasalahan tools yang akan digunakan adalah sebagai beriku :

a. Diagram Sebab Akibat (Cause and Effect Diagram)

Diagram sebab akibat digunakan untuk melihat sejumlah kemungkin yang menyebabkan permasalahan yang terjadi pada proses. Informasi tentang hal-hal yang menyebabkan permasalahan tersebut diperoleh dari hasil wawancara dengan kepala produksi dan bagian produksi. Untuk lebih jelasnya penyebab-penyebab dari masalah cacat dapat dilihat pada diagram sebab akibat berikut yang disajikan pada Gambar 3. 


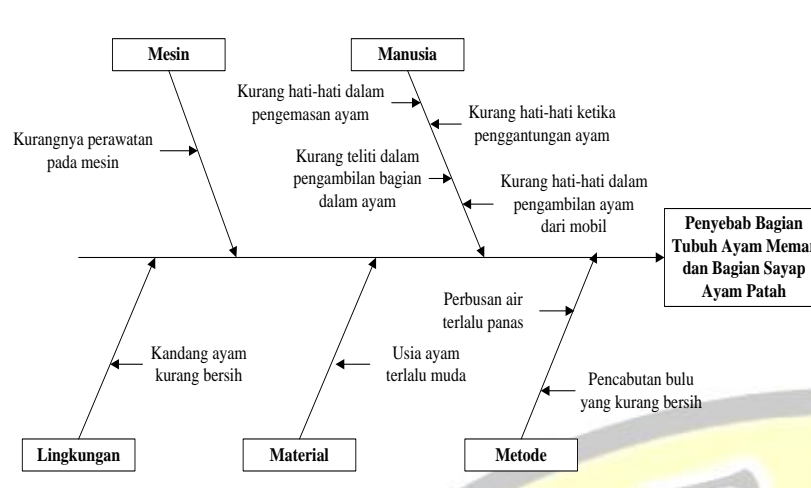

\begin{tabular}{ccccccccc}
\hline 4 & 327 & 1 & 40 & 60 & 0 & 0 & 101 & 0,31 \\
\hline 5 & 327 & 1 & 27 & 56 & 0 & 0 & 84 & 0,26 \\
\hline 6 & 327 & 0 & 54 & 88 & 3 & 0 & 145 & 0,44 \\
\hline 7 & 327 & 0 & 36 & 79 & 1 & 0 & 116 & 0,35 \\
\hline 8 & 327 & 3 & 35 & 81 & 2 & 0 & 121 & 0,37 \\
\hline 9 & 327 & 1 & 42 & 66 & 1 & 2 & 112 & 0,34 \\
\hline 10 & 327 & 0 & 22 & 89 & 0 & 0 & 111 & 0,34 \\
\hline 11 & 327 & 1 & 59 & 70 & 0 & 3 & 133 & 0,41 \\
\hline 12 & 327 & 3 & 61 & 52 & 0 & 0 & 116 & 0,35 \\
\hline 13 & 327 & 1 & 56 & 64 & 0 & 1 & 122 & 0,37 \\
\hline 14 & 327 & 2 & 70 & 71 & 0 & 0 & 143 & 0,44 \\
\hline 15 & 327 & 2 & 49 & 58 & 0 & 1 & 110 & 0,34 \\
\hline 16 & 327 & 3 & 52 & 40 & 0 & 0 & 95 & 0,29 \\
\hline 17 & 327 & 1 & 46 & 51 & 1 & 0 & 99 & 0,30 \\
\hline 18 & 327 & 4 & 56 & 48 & 0 & 0 & 108 & 0,33 \\
\hline 19 & 327 & 2 & 44 & 57 & 0 & 0 & 103 & 0,31 \\
\hline 20 & 327 & 1 & 51 & 57 & 2 & 0 & 111 & 0,34 \\
\hline Total & $\mathbf{6 5 4 0}$ & $\mathbf{2 9}$ & $\mathbf{9 6 0}$ & $\mathbf{1 2 2 5}$ & $\mathbf{1 2}$ & $\mathbf{7}$ & $\mathbf{2 2 3 3}$ & $\mathbf{6 , 8 1}$ \\
\hline Rata- & $\mathbf{3 2 7}$ & $\mathbf{1 , 4 5}$ & $\mathbf{4 8}$ & $\mathbf{6 1 , 2 5}$ & $\mathbf{0 , 6}$ & $\mathbf{0 , 3 5}$ & $\mathbf{1 1 1 , 6}$ & $\mathbf{0 , 3 4 1}$ \\
$\mathbf{R a t a}$ & & & & $\mathbf{5}$ & & \\
\hline
\end{tabular}

Gambar 3. Diagram Sebab Akibat Tubuh Ayam Memar dan Bagian Sayap Ayam Patah

Berdasarkan diagram sebab akibat diatas dapa dilihat bahwa faktor penyebab bagian tubuh ayan memar dan bagian sayap ayam patah adalah :

1) Faktor manusia

\begin{tabular}{|c|c|c|c|c|c|c|c|c|c|}
\hline \multirow{3}{*}{ a) Kurang hati-hati dalam pengambila_ } & & & & & & & & & \\
\hline & 19 & 327 & 2 & 44 & 57 & 0 & 0 & 103 & 0,31 \\
\hline & 20 & 327 & 1 & 51 & 57 & 2 & 0 & 111 & 0,34 \\
\hline Kurang hati-hati & Total & 6540 & 29 & 960 & 1225 & 12 & 7 & 2233 & 6,81 \\
\hline $\begin{array}{l}\text { ayam } \\
\text { Kurang teliti dala }\end{array}$ & $\begin{array}{l}\text { Rata- } \\
\text { Rata }\end{array}$ & 327 & 1,45 & 48 & 61,25 & 0,6 & 0,35 & $\begin{array}{c}111,6 \\
5\end{array}$ & 0,341 \\
\hline
\end{tabular}
dalam ayam

d) Kurang hati-hati dalam pengemasan ayam

Sumber : Hasil Survey Data Primer (2018)

2) Faktor mesin

a) Kurangnya perawatan pada mesin

3) Faktor metode

a) Perebusan air terlalu panas

b) Pencabutan bulu yang kurang bersih

4) Faktor material

a) Usia ayam terlalu muda

5) Faktor lingkungan

1) Kandang ayam kurang bersih

b. Kapabilitas Proses Menggunakan Peta Kontrol P Pengukuran kapabilitas proses dilakukan untuk mengetahui kapabilitas dari data cacat yang dihasilkan dalam kondisi kapabel. Data tersebut dapat dilihat pada Tabel 3.

Tabel Hasil Pemotongan Ayam yang Cacat Selama 20

$$
\text { Hari }
$$

\begin{tabular}{|c|c|c|c|c|c|c|c|c|}
\hline \multirow[b]{2}{*}{ Hari } & \multirow[b]{2}{*}{$\begin{array}{c}\text { Jenis } \\
\text { Samp } \\
\text { el }\end{array}$} & \multicolumn{5}{|c|}{$\begin{array}{l}\text { Janis Cacat pada Hasil } \\
\text { Pemotongan Ayam }\end{array}$} & \multirow{2}{*}{$\begin{array}{c}\text { Juml } \\
\text { ah } \\
\text { Ayam } \\
\text { Cacat }\end{array}$} & \multirow{2}{*}{$\begin{array}{c}\text { Propor } \\
\text { si } \\
\text { Hasil } \\
\text { Pemot } \\
\text { ongan } \\
\text { Ayam } \\
\text { yang } \\
\text { Cacat }\end{array}$} \\
\hline & & A & B & C & D & $\mathbf{E}$ & & \\
\hline 1 & 327 & 2 & 57 & 39 & 1 & 0 & 99 & 0,30 \\
\hline 2 & 327 & 0 & 48 & 52 & 1 & 0 & 101 & 0,31 \\
\hline 3 & 327 & 1 & 55 & 47 & 0 & 0 & 103 & 0,31 \\
\hline
\end{tabular}

Keterangan : A = Bagian kepala ayam memar

$$
\mathrm{B}=\text { Bagian sayap ayam patah }
$$$$
\mathrm{C}=\text { Bagian tubuh ayam memar }
$$$$
\mathrm{D}=\text { Pencabutan bulu yang kurang bersih }
$$

$\mathrm{E}=$ Pengambilan bagian dalam kurang bersih

Dari Tabel 4.3 dapat diketahui semua rata-rata mulai dari jumlah sampel sebesar 327 , jenis cacat ayam (bagian kepala ayam memar $(1,45)$, bagian sayap ayam patah (48), bagian tubuh ayam memar $(61,25)$, pencabutan bulu yang kurang bersih $(0,6)$, dan pengambilan bagian dalam kurang bersih $(0,35))$, jumlah ayam yang cacat 111,65 dan proporsi ayam yang cacat 0,341 .

Langkah selanjutnya menghitung rata-rata total proporsi ayam yang cacat menggunakan rumus sebagai berkut :

$$
\begin{aligned}
p & =\frac{\sum n p}{\sum n} \\
& =\frac{\sum 6,81}{\sum 20}=0,3405
\end{aligned}
$$


Setelah di ketahui rata-rata total proporsi selanjutnya menghitung batas kendali at as atau UCL (Upper Control Limit) dan batas kendali bawah atau LCL (Lower Control Limit). Untuk mengetahui nilai tersebut maka digunakan rumus sebagai berikut :

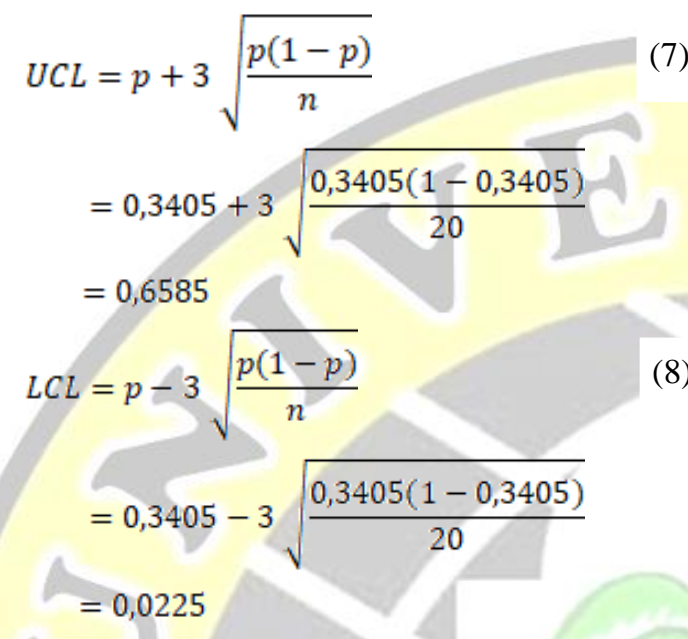

(8)

Selanjutnya akan dibuat peta kendali agar kendali cacat produk dapat dilihat berdasarkan grafik. Berikut disajikan grafik Peta Kontrol P.

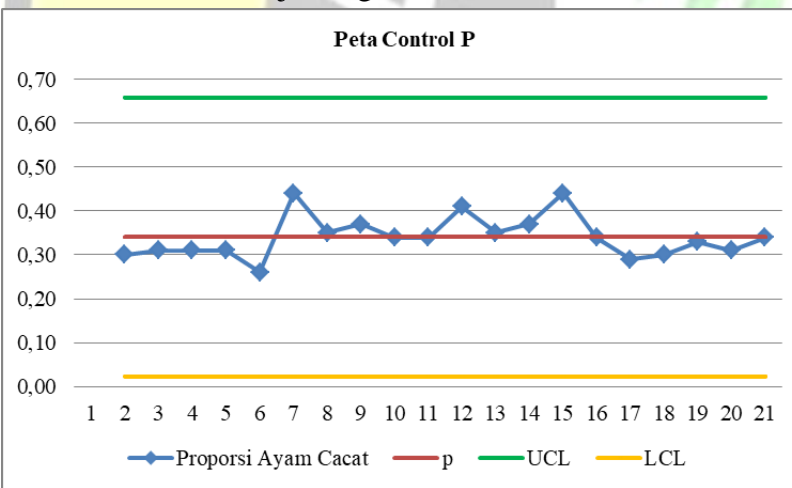

Gambar 4. Peta Kontrol P Cacat Hasil Potong Ayam

Dari Gambar 4 di atas dapat diketahui bahwa proporsi cacat pada produk pemotongan ayam dinilai relatif terkendali, hal tersebut dapat dilihat berdasarkan garis kecacatan yang masih berada di dalam batas kendali. Dari grafik tersebut juga diketahui bahwa batas kendali atas (UCL) sebesar 0,6585 dan batas kendali bawah (LCL) sebesar 0,0225 dengan $\mathrm{P}$ (Rata-rata proporsi kecacatan produk) sebesar 0,3405. Sehingga dari grafik tersebut dapat diketahui bahwa produk pemotongan ayam di PT. Gemilang Inti Sukses (GIS) masih terjadi kecacatan produk pada proporsi rata-rata 0,34 , oleh sebab itu PT. Gemilang Inti Sukses (GIS) perlu melakukan peningkatan kualitas agar dapat mencapai kontrol proporsi maksimum yaitu $0 \%$ kecacatan.

4. Fase Improve

pada fase Analyza, selanjutnya dilakukan tindakan untuk mengatasi masalah-masalah yang ada. Perbaikan yang harus dilakukan antara lain adalah :

a. Perbaikan kecacatan berdasarkan faktor manusia Dari penyebab kecatatan produk berdasarkan faktor manusia tersebut dapat dilakukan tindakan perbaikan yaitu pertama dilakukan refresing antara pekerja dengan atasan minimal 1 bulan sekali untuk menyegarkan tenaga para pekerja sekaligus menjalin komunikasi yang baik antara pekerja dengan atasan, kedua dilakukan rolling internal dalam satu bagian minimal setiap 3 bulan sekali dan ketiga pemberian reward kepada pekerja untuk mengembalikan semangat bekerja para pekerja.

b. Perbaikan kecatatan berdasarkan faktor mesin Solusi untuk mengatasi kecacatan yang disebabkan oleh mesin dapat dilakukan dengan pemeliharaan mesin dan pengecekan mesin setiap hari supaya mesin selalu dalam keadaan siap pakai.

c. Perbaikan kecacatan berdasarkan faktor material Agar memperoleh bahan baku ayam yang bagus maka seharusnya perusahaan memiliki kandang peternakan ayam sendiri supaya dapat mengecek usia maupun kesehatan ayam secara teratur.

d. Perbaikan kecacatan berdasarkan faktor metode Dalam hal ini masukan yang diberikan adalah dengan mengadakan pelatihan kepada karyawan minimal 3 bulan sekali untuk menunjukan kepada karyawan teknik perebusan ayam dan pencabutan bulu ayam yang baik.

e. Perbaikan kecacatan berdasarkan faktor lingkungan

Dalam hal ini perbaikan yang harus dilakukan adalah evaluasi terhadap petugas kandang agar melakukan perawatan kandang secara maksimal.

\section{PENUTUP}

\section{Simpulan}

Berdasarkan hasil dan pembahasan maka diperoleh kesimpulan sebagai berikut :

1. Identifikasi pengendalian kualitas pemotongan ayam menggunakan metode Six Sigma pada konsep DMAIC (Define, Measure, Analyze, Improve and Control) di PT. Gemilang Inti Sukses ini dilaksanakan pada tahap Define. Dari hasil identifikasi diketahui jumlah data hasil pemotongan ayam yang cacat selama 4 minggu sebanyak 2.230 ekor ayam yang terdiri dari lima jenis cacat yaitu pada bagian kepala 
ayam memar sebanyak 29 ekor, bagian sayap ayam patah sebanyak 960, bagian tubuh ayam memar sebanyak 1.225, pencabutan bulu kurang bersih sebanyak 12 ekor, dan pengambilan bagian dalam yang kurang bersih sebanyak 4 ekor. Dalam 4 minggu tersebut jenis cacat yang paling banyak terdapat pada bagian tubuh ayam yang memar, dan yang paling sedikit terdapat pada cacat pengambilan bulu yang kurang bersih.

2. Hasil kualitas pemotongan ayam menggunakan metode Six Sigma diketahui dari pengukuran baselin kinerja perusahaan bahwa kondisi perusahaan berada pada level sigma 3,85 dengan nilai DPMO 9.292, yang artinya dalam 1 juta potong ayam terdapat 9.292 ekor ayam yang cacat. Selanjutnya dari proses tersebut disusun pareto yang diketahui bahwa $80 \%$ penyebab cacat adalah bagian sayap ayam patah dan bagian tubuh ayam memar. Kemudian dari diagram sebab-akibat diketahui dari 2 faktor cacat terbesar yakni bagian tubuh ayam memar dan bagian sayap ayam patah disebabkan utama oleh faktor sumber daya manusia. Pada diagram peta kontrol diperoleh batas kendali atas (UCL) sebesar 0,6585 dan batas kendali bawah (LCL) sebesar 0,0225 dengan P (Ratarata proporsi kecacatan produk) sebesar 0,3405, artinya hasil pemotongan ayam di PT. Gemilang Inti Sukses masih terjadi kecacatan produk pada proporsi rata-rata 0,34 sehingga perusahaan tersebut perlu melakukan peningkatan kualitas agar dapat mencapai kontrol proporsi maksimum yaitu $0 \%$ kecacatan. Pada fase Improve dan fase Control perusahaan perlu melakukan peningkatan kualitas dengan kedisiplinan yang lebih terhadap standar operasional sumber daya manusia dan melakukan pengawasan serta evaluasi kinerja karyawan.

\section{Saran}

Berdasarkan kesimpulan yang telah diperoleh, maka penulis ingin memberikan saran kepada perusahaan dan peneliti lain yang ingin melakukan penelitian dibidang yang sama, antara lain:

1. Diharapkan dengan diadakannya penelitian ini di perusahaan yang bersangkutan dapat memberikan efek positif. Perusahaan dapat melakukan kedisiplinan mengenai standart operasional perusahaan, terhadap staff dan karyawan perusahaan agar hasil produksi tetap terjaga kualitasnya.

2. Penelitian yang dilakukan masih kurang sempurna karena pada fase Define hanya difokuskan pada hasil potong ayam yang cacat dan pada fase Improve usulan yang diberikan kepada perusahaan masih berupa tindakan umum yang dapat dilaksanakan oleh perusahaan. Peneliti lain dapat melanjutkan penelitian ini dengan membandingkan hasil nilai DPMO dari penelitian ini dengan peneliti selanjutnya.

\section{DAFTAR PUSTAKA}

Nailah. Harsosno, Ambar. dan Liansari, Gita Permata. 2014. "Usulan Perbaikan Untuk Mengurangi Jumlah Cacat pada Produk Sandal Eiger S-101 Lightspeed dengan Menggunakan Metode Six Sigma”. Jurnal Teknik Industri Itenas. Vol. 02 (02): hal 256-267.

Prawira, Yoga. 2014. Analisis Pengendalian Kualitas Produk pada PT. Pundi Miranti dengan Pengdekatan Six Sigma. Skripsi. Bogor: Institut Pertanian Bogor.

Purnomo, Hari. 2004. Pengantar Teknik Industri. Edisi Kedua. Yogyakarta: Graha Ilmu.

Putra, Wicaksono. Analisis Statistika, (online), (http://analisisstatistika.blogspot.com/2012/09/menentukan-jumlahsampel-dengan-rumus.html, diakses 06 Juni 2018).

Soemohadiwidjojo, Arini T. 2017. Six Sigma "Metode Pengukuran Kinerja Perusahaan Berbasis Statistika”. Jakarta : Raih Asa Sukses.

Tannady, Hendi. 2015. Pengendalian Kualitas. Yogyakarta: Graha Ilmu.

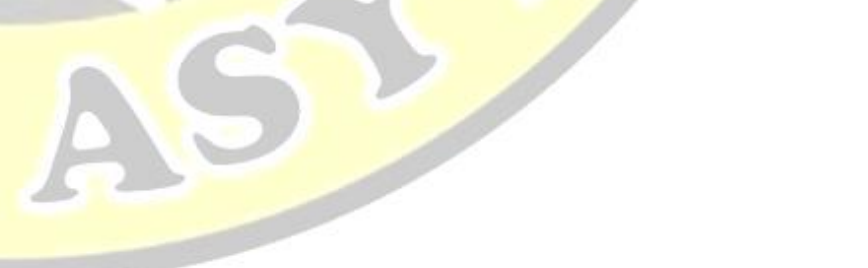

